\title{
Imprescindibilidade da Intervenção do Ministério Público Na Usucapião ${ }^{1}$
}

\author{
Ednéa Teixeira Magalhães² \\ Zilda Carolina Dias Paiva Cândido ${ }^{3}$
}

\section{RESUMO}

A Lei n 13.105, de 16 de março de 2015, que institui o Novo Código de Processo Civil, retirou a usucapião dos procedimentos especiais de jurisdição contenciosa, passando a fazer parte do procedimento ordinário, além de inovar no instituto da usucapião extrajudicial, de natureza administrativa. Suprimiu, ainda, o artigo que tratava da intervenção do Ministério Público na ação de usucapião. Abordaremos nesse artigo a intervenção do Ministério Público na usucapião tanto judicial quanto extrajudicial como forma de fiscalizar o ordenamento jurídico, tendo em vista a usucapião como forma de concretização da função social da propriedade e do direito à moradia. Analisaremos, por último, os pontos polêmicos acerca da usucapião extrajudicial.

Palavras-chave: Processo Civil. Usucapião. Intervenção do Ministério Público. Função social da propriedade. Lei no 13.105/2015.

\section{INTRODUÇÃO}

Durante a vigência do Código Processual Civil, Lei n 5.869 de 11 de janeiro de 1973, a usucapião era prevista como procedimento de

\footnotetext{
1 Data de recebimento: 18/05/2017. Data de aceite: 02/06/2017.

2 Membro do Ministério Público do Estado do Ceará. Professora de Direito Processual Civil na Universidade de Fortaleza. Mestre em Direito pela Universidade de Fortaleza. E-mail: edneatm@unifor.br 3 Assessora Jurídica Especial do Ministério Público do Estado do Ceará. Bacharel em Direito. Pós-graduada em Direito Tributário pela Fundação Getúlio Vargas. E-mail: zildacarolina@gmail.com
} 
jurisdição especial contenciosa. Com o advento do Novo Código de Processo Civil, Lei 13.105, de 16 de março de 2015, passou a ser um procedimento ordinário, uma vez que era a audiência de justificação prévia, há muito abolida através da Lei 8.951/94, que tornava esse instituto especial.

O atual Código de Processo Civil ampliou os conceitos da usucapião extrajudicial, de natureza administrativa, e retirou de forma expressa a exigibilidade da intervenção do Ministério Público como fiscal de todos os atos do processo da usucapião.

Resta analisar se realmente torna-se dispensável a participação do Ministério Público como fiscal da ordem jurídica, uma vez que a propriedade é direito individual e disponível, e a sua função social deve atender ao interesse público, a fim de concretizar o direito de moradia, reduzindo as desigualdades sociais, bem como evitar o crescimento das favelas, sejam urbanas ou rurais.

Vale observar também se a atividade exercida pelo tabelião na usucapião extrajudicial traz imparcialidade e segurança jurídica, tendo em vista a complexidade dos requisitos exigidos para o cumprimento de todos os pressupostos legais.

Portanto, o presente artigo tem como objetivo analisar a relevância da intervenção do Ministério Público na ação de usucapião, seja judicial ou de forma administrativa.

Para a elaboração deste trabalho realizou-se um estudo bibliográfico, com base na doutrina processual civil brasileira e na Lei no 13.105/2015. Os métodos empregados foram o analítico-sintético, que consiste na compreensão e aprofundamento de um texto geral pelo estudo minucioso de suas partes, necessário aqui para o entendimento não só da doutrina, mas da lei processual civil em foco; e o método comparado, que será aplicado no estudo do artigo que trazia expressamente a exigência da intervenção do Ministério Público nas ações de usucapião e sua supressão no novo Código de Processo Civil, com a finalidade de apresentarmos as mudanças introduzidas na mencionada lei. 
O tipo de pesquisa utilizada foi a bibliográfica, ou seja, por meio de livros, monografias, artigos científicos, revistas, boletins, dentre outras pesquisas que foram disponibilizadas em bibliotecas e na internet.

\section{USUCAPIÃO}

Um aspecto interessante é examinar o gênero do vocábulo "usucapião", se masculino, se feminino ou se os dois gêneros podem ser empregados. Vale observar que a Constituição Federal de 1988, em seus artigos 183, §3º e 191, parágrafo único, não aplica nenhum artigo ou especificador que evidencie o gênero escolhido para a palavra. Entretanto, o Código Civil, posterior à Constituição Federal, em vigor desde 11 de janeiro de 2003, acolheu a expressão "da usucapião" (Seção I dos Capítulos II e III, do título III do Livro III), dirimindo, assim, uma dúvida que perdurou por bastante tempo.

Usucapião é um modo de aquisição originária da propriedade em decorrência do lapso temporal. É originário porque a aquisição não se dá por transmissão de proprietário anterior, e sim pelo cumprimento dos requisitos objetivos previstos na lei. Por ser forma originária de aquisição da propriedade, não se paga imposto de transmissão inter vivos. A usucapião pode estender-se à aquisição de outros direitos reais, tais como as servidões, o usufruto, o uso, a superfície e a habitação.

Neves assim conceitua a usucapião:

"O instituto trata tanto da aquisição de bens móveis quanto imóveis, embora seja inegável estar predominantemente ligado à aquisição da propriedade imobiliária. Não podem ser objeto de usucapião bens que não podem ser objeto de posse, como os incorpóreos e os fora do comércio, que são inalienáveis e insuscetíveis de apropriação, tais como os bens públicos (de uso comum, de uso especial e dominiais) e as terras devolutas". (NEVES, 2012, p. 1387). 
O fundamento da usucapião reside no fato de que todo bem, móvel ou imóvel, tem uma função social, devendo ser aproveitado pelo proprietário, direta ou indiretamente, de modo a gerar utilidades. Segundo Salles:

...assim, o proprietário desidioso, que não cuida do que é seu, que deixa seu bem em estado de abandono, ainda que não tenha intenção de abandoná-lo, perde sua propriedade em favor daquele que, havendo se apossado da coisa, mansa e pacificamente, durante o tempo previsto em lei, da mesma cuidou e lhe deu destinação, utilizando-a como se sua fosse. (SALLES, 1997, p.31).

Para que seja concedido o direito à usucapião, é necessário que certos requisitos previstos no Código Civil, Código de Processo Civil, Lei de Registros Públicos (Lei 6.015 de 31 de dezembro de 1973) e na Constituição Brasileira sejam observados.

A sentença de uma ação de usucapião é meramente declaratória, e o registro da sentença dá-lhe publicidade, ou seja, a anotação no álbum imobiliário não é constitutiva do direito, apenas autoriza a dispor do bem como proprietário declarado.

A usucapião serve, ainda, para consolidar as aquisições, pacificar os conflitos, dar segurança e estabilidade à propriedade, como bem salienta Salles:

Interessa à paz social a consolidação daquela situação de fato na pessoa do possuidor, convertendo-a em situação de direito, evitando-se, assim, que a instabilidade do possuidor possa eternizar-se, gerando discórdias e conflitos que afetem perigosamente a harmonia da coletividade. (SALLES, 2005, p. 49).

Assim, a usucapião é um instrumento de pacificação social, auxiliando na concretização da função social da propriedade, num país onde a disputa por terras contribuiu para a matança de pessoas inocentes. Entre as causas que motivaram a existência destes conflitos, 
podemos citar a negligência do Estado em não promover a reforma agrária, o que facilitou o crescimento das favelas, tanto no setor urbano como no rural e a especulação imobiliária em detrimento da concretização do direito à moradia.

\subsection{Espécies de usucapião}

A legislação brasileira admite a usucapião tanto sobre bens imóveis quanto bens móveis. O bem móvel pode ser adquirido através da usucapião ordinária, prevista no artigo 1.260 do Código Civil, e da extraordinária, no artigo 1.261 do mesmo Código.

Com relação aos bens imóveis, são eles: extraordinário, ordinário e especial (rural e urbana), coletivo, familiar, indígena e extrajudicial.

A usucapião extraordinária está prevista no artigo 1.238 do Código Civil, e entre os seus requisitos estão: a posse mansa, pacífica e ininterrupta com animus domini, comportando o prazo de 15 anos, cuja posse independe de justo título e boa-fé, ou 10 anos caso o possuidor tenha estabelecido no imóvel sua moradia habitual ou nele realizado obras ou serviço de caráter produtivo.

A expressão animus domini faz referência à forma em que o possuidor exerce a sua posse sobre o bem, devendo ter um comportamento como se proprietário fosse, com intenção de tornar-se ou mesmo acreditar ser o dono do bem. Sobre o assunto, Gonçalves explica:

Não tem ânimo de dono o locatário, o comodatário e todos aqueles que exercem posse direta sobre a coisa, sabendo que não lhe pertence e com reconhecimento do direito dominial de outrem, obrigando-se a devolvê-la. Ressalve que é possível ocorrer a modificação do caráter da posse, quando, acompanhando a mudança da vontade, sobrevém uma nova causa possessionis (GONÇALVES, 2006, p. 99).

A usucapião ordinária está prevista no artigo 1.242 do Código 
Civil, tendo como requisitos a posse contínua, incontestável, com justo título e boa-fé, exercida de forma mansa e pacífica pelo lapso temporal de 10 anos. Esse prazo pode ser reduzido para 5 anos se o imóvel foi adquirido onerosamente, com base no registro constante do respectivo cartório e cancelada posteriormente, sendo necessário ainda que os possuidores residam no imóvel ou tenham realizado investimentos de interesse social e econômico.

A Constituição Federal prevê duas espécies de usucapião de bem imóvel para atender aos possuidores de imóveis urbanos ou rurais, desde que estes os utilizem, respectivamente, para moradia e para sua sobrevivência econômica.

A usucapião especial urbana, também conhecida por pró-moradia, é prevista no artigo 183 da Constituição e no artigo 1.240 do Código Civil e possui características próprias que ressaltam o seu caráter social. A legitimidade é exclusiva a pessoas físicas que não tenham título de propriedade de outro imóvel urbano ou rural, não podendo o direito à usucapião ser concedido mais de uma vez ao mesmo possuidor. Ademais, a área urbana a ser usucapida limita-se a $250 \mathrm{~m}^{2}$ (duzentos e cinquenta metros quadrados). O lapso temporal para aquisição nessa modalidade é 5 anos.

A usucapião especial rural, prevista no artigo 191 da Constituição Federal e no artigo 1.239 do Código Civil, requer o lapso temporal de 5 anos ininterruptos, sem oposição, área de terra em zona rural, não podendo ser superior a 50 hectares, sendo vedada a posse sobre qualquer outro bem imóvel. Além disso, deve ter por finalidade tornar a terra produtiva por seu trabalho ou de sua família, fixando nela a sua moradia, podendo ser chamada de pró-labore.

A usucapião coletiva, criada pela Lei 10.257, de 10 de julho de 2001, que regulamentou os artigos 182 e 183 da Constituição Federal, tem como requisitos a ocupação por 5 anos ininterruptos e sem oposição, devendo a área do imóvel usucapiendo ter mais de $250 \mathrm{~m}^{2}$ (duzentos e cinquenta metros quadrados), não podendo os requeren- 
tes ser proprietários de outro bem imóvel urbano ou rural. As áreas urbanas devem ser ocupadas por população de baixa renda, não sendo possível identificar os terrenos ocupados por cada possuidor. Por último, o imóvel deve ser objeto de moradia.

A usucapião familiar encontra-se capitulada no artigo 1.240-A do Código Civil, pode ser deferida àquele que exercer, por 2 (dois) anos ininterruptamente e sem oposição, posse direta, com exclusividade, sobre imóvel urbano de até $250 \mathrm{~m}^{2}$ (duzentos e cinquenta metros quadrados) cuja propriedade dividida com ex-cônjuge ou ex-companheiro que abandonou o lar, utilizando-o para sua moradia ou de sua família, adquirir-lhe-á o domínio integral, desde que não seja proprietário de outro imóvel urbano ou rural, conforme o dispositivo legal anteriormente mencionado.

A usucapião indígena, prevista no artigo 33 do Estatuto do Índio (Lei 6.001 de 19 de dezembro de 1973), possui os mesmos pressupostos das demais espécies, com exceção do justo título e boa-fé que são exigidos na usucapião ordinária, sendo eles animus domini, posse mansa e pacífica, ininterrupta. O lapso temporal é de 10 anos consecutivos, e o imóvel tem que ser inferior a 50 (cinquenta) hectares. Tanto índio integrado à civilização, como os que vivem na selva, podem requerer esse tipo de usucapião.

Por último, a usucapião extrajudicial foi realmente regulamentada e dotada de feições próprias pelo Novo Código de Processo Civil, Lei 13.105 de 16 de março de 2015, o qual acrescentou o artigo 216-A à Lei de Registros Públicos.

Essa modalidade de usucapião possui natureza administrativa, e não jurisdicional, não induzindo litispendência e nem possuindo característica típica da jurisdição.

Não se trata de instituto inédito no ordenamento jurídico brasileiro, pois já era prevista na Lei 11.977/2009, que tinha por objeto a regularização fundiária de interesse social, bem como existe o Decreto-lei n 87.620, de 21 de setembro de 1982, que dispõe sobre 
o procedimento administrativo a fim de assegurar o reconhecimento da aquisição, por usucapião especial, de imóveis rurais compreendidos em terras devolutas. Contudo, o Novo Código de Processo Civil ampliou e regularizou essa modalidade de usucapião, que será processada diretamente perante o cartório de registro de imóveis na comarca onde estiver localizado o imóvel. É imprescindível a representação por advogado ou defensor, e o tabelião atestará o tempo de posse do requerente e de seus antecessores.

O artigo 216-A da Lei de Registros Públicos também prevê os requisitos comuns exigíveis a todas as espécies de usucapião de bens imóveis, quando requer que sejam anexados aos autos: planta e memorial descritivo, assinado por profissional legalmente habilitado; certidões negativas com a finalidade de saber se o imóvel encontra-se registrado; intimação da União, do Estado, do Distrito Federal e dos Municípios para manifestaram interesse no feito; publicação de edital para dar ciência a terceiros e eventuais interessados.

Segundo os ensinamentos de Brandelli:

Não há limitação no art. 216-A da LRP quanto à espécie de usucapião que possa ser reconhecida pela usucapião extrajudicial, tampouco há alguma incompatibilidade por conta da natureza jurídica de alguma espécie, de modo que qualquer espécie de prescrição aquisitiva pode ser reconhecida extrajudicialmente se presentes os requisitos para tanto.

Qualquer aquisição de direito real imobiliário usucapível poderá $\square$ ser reconhecida na via extrajudicial, se presentes a posse ad usucapionem pelo tempo adequado, aliada aos demais requisitos eventualmente exigidos, a depender da espécie de usucapião. (BRANDELLI, 2016, p.24).

Sendo a usucapião uma ação real imobiliária, o cônjuge necessitará do consentimento do outro para propor ação, salvo quando casado sob o regime de separação absoluta de bens, conforme artigo 73 do Novo Código de Processo Civil.

Outro requisito exigido à usucapião é a citação pessoal dos 
confinantes ${ }^{4}$, salvo quando tiver por objeto unidade autônoma de prédio em condomínio, assim como a publicação de edital também é necessária na ação de usucapião imóvel, conforme artigos 246, §3 e 259, I do Novo Código de Processo Civil, respectivamente.

A nomeação de curador de ausentes só será necessária quando o réu certo e determinado encontrar-se em lugar incerto ou não sabido. Por exemplo, o imóvel usucapiendo encontra-se registrado em nome de uma pessoa que não se sabe o paradeiro. O mesmo acontece quando se tratar de o confinante certo e determinado encontrar-se em lugar incerto.

Atendidos os requisitos legais para o requerimento da usucapião, seu objetivo é a utilidade social, pois é fundamental que cada coisa tenha um dono, que cuide dela de acordo com o interesse geral da sociedade. Assim, o proprietário que abandona um bem é preterido pelo direito, em favor daquele que dá à coisa destinação social de utilidade.

\subsection{Função social da propriedade e o direito à moradia}

A propriedade tem seguido a evolução do Estado, e este a evolução do próprio homem, onde o Estado Liberal não era capaz de atender às demandas coletivas. Assim, com o fim da Primeira Guerra Mundial, surgiu um novo modelo de Estado, denominado Estado Social, tendo por objetivo a concretização dos direitos fundamentais de segunda dimensão ou geração, buscando a redução das desigualdades sociais existentes, através de prestações positivas do Estado (Cunha; Novelino, 2015, p. 169).

No Brasil, desde a Constituição do Império, 1824, que é garantido o uso da propriedade, limitada no sentido de poder ser desapropriada por necessidade ou utilidade pública. A Constituição de 1934 foi pioneira em relacionar os termos propriedade e função social. Com

4 Súmula 391, STF: O confinante certo deve ser citado, pessoalmente, para a ação de usucapião. 
o advento da Constituição de 1988, foi introduzido o direito fundamental à propriedade, inovando com a expressão "função social da propriedade", nos artigos 5 XXIII, 170, III, 182, parágrafo segundo e 186, caput. Segundo Bulos:

A função social da propriedade, para compatibilizar-se com a almejada justiça constitucional, deve desempenhar destino economicamente útil, isto é, produtivo, com vistas à satisfação das necessidades sociais preenchíveis pela espécie tipológica do bem, canalizando suas potencialidades em benefício de todos, sem qualquer distinção. (BULOS, 2007, p. 197).

No Código Civil de 1916, artigo 524, “a lei assegura ao proprietário o direito de usar, gozar e dispor de seus bens e de reavê-los do poder de quem quer que injustamente os possua". O Código não conceitua o que é propriedade, limitando-se apenas a elencar os direitos que asseguram aos proprietários.

O atual Código Civil, artigo 1.228, também não define a propriedade, apenas dispõe sobre os direitos que o proprietário pode exercer sobre o imóvel, ou seja, usar, gozar e dispor da coisa, e o direito de reavê-la de quem quer que injustamente a possua ou detenha. Esse direito deve ser exercido em consonância com as suas finalidades econômicas e sociais e de modo que sejam preservados a flora, a fauna, as belezas naturais, o equilíbrio ecológico e o patrimônio histórico e artístico, bem como evitada a poluição do ar e das águas.

Assim, com a evolução dos tempos, do homem e do próprio Estado, foi constatado que era impossível viver em sociedade sem respeitar os direitos novos surgidos em decorrência da vida social dos povos, como os direitos transindividuais coletivos e difusos. Tornou-se necessário também limitar o direito de propriedade individual a fim de favorecer um interesse maior, que é o da sociedade.

Sobre a função social da propriedade, Maluf ensina:

O princípio da função social da propriedade, enquanto princípio ordenador da propriedade privada, é largamente utilizado em matéria urbanística. Reafirmado diversas 
vezes pela Lei Maior, representa uma limitação ao direito de propriedade, no sentido de que compõe o próprio perfil desse direito. O proprietário deve usar e desfrutar do bem exercendo esse direito em prol da coletividade. (MALUF, 2010, p. 60-61).

A usucapião urbana, rural e coletiva exigem outros requisitos específicos, pois têm como objetivo atender aos princípios e direitos sociais constitucionais, como o cumprimento da função social da propriedade e o direito à moradia.

A Declaração Universal dos Direitos Humanos de 1948 já trata do direito à moradia, em seu artigo 25, 1, onde estabelece que toda pessoa tem direito a um nível de vida suficiente para que lhe seja assegurado, bem como à sua família, a saúde e o bem-estar, principalmente quanto à alimentação, ao alojamento, dentre outros direitos sociais.

O Pacto Internacional de Direitos Econômicos, Sociais e Culturais, em seu artigo 11, I, reconhece o "direito de toda pessoa a um nível de vida adequado para si próprio e sua família, inclusive à alimentação, vestimenta e moradia adequadas, assim como a uma melhoria contínua de suas condições de vida".

Na Constituição de 1988, o direito à moradia foi incluído através da Emenda Constitucional no 26/2000. Assim, esse direito resulta do Estado Social, onde os poderes públicos devem criar medidas de forma a concretizar e atender as necessidades coletivas, de modo a promover igualdade política e social, consagrando o princípio da dignidade da pessoa humana.

\section{O MINISTÉRIO PÚBLICO COMO FISCAL DA ORDEM JURÍDICA NA AÇÃO DE USUCAPIÃO}

Em breve análise histórica, da origem e evolução do Ministério Público, observa-se por meio de pesquisas realizadas no Egito há 
mais de 4 (quatro) mil anos, que o Parquet exercia a função real, que era considerada como "língua e os olhos do rei". (Mazilli, 1991, p. 1).

Através da Constituição Federal, o Ministério Público conseguiu ocupar a função de defensor dos direitos sociais, dos povos indígenas e das minorias. Além de fiscalizar o ordenamento jurídico, promove privativamente a ação penal pública, defende a ordem jurídica, o regime democrático e os interesses individuais indisponíveis, bem como os direitos transindividuais, sejam coletivos, difusos ou individuais homogêneos. Busca também, através do exercício de suas funções, não só a aplicação do Direito, mas implantar a justiça.

É um órgão que possui a finalidade de representar a sociedade, fiscalizando o efetivo cumprimento da Constituição e das leis pelos governantes eleitos, e perante o Poder Judiciário, quando a demanda interessar à sociedade. Como bem atualizou o Novo Código de Processo Civil, o Ministério Público atuará na defesa da ordem jurídica, na qualidade de fiscal, conforme artigo 176, não deixando de exercer também o seu direito de ação.

O Ministério Público age em nome próprio, defendendo interesse alheio, assumindo a posição de substituto processual. Quando se manifesta, busca a concretização dos interesses e direitos sociais e individuais indisponíveis.

Como bem enfatiza Gonçalves, existem três hipóteses que justificam a atuação do Ministério Público como fiscal da ordem jurídica. São elas, segundo o artigo 178 do Novo Código de Processo Civil: quando houver interesse público ou social, interesse de incapazes e nas ações que envolvam litígios coletivos pela posse da terra rural e urbana.

Um exame dessas hipóteses permite distinguir duas categorias: aquelas em que a intervenção ministerial é justificada pelo objeto discutido no processo; e aquelas em que o é pela qualidade de uma das partes. Por isso, parcela da doutrina faz a distinção entre a intervenção ministerial como efetivo fiscal da ordem jurídica (...) e como auxiliar da parte (...). (GONÇALVES, 2016, p.279). 
Sobre o assunto, Ferraz e Guimarães Júnior ensinam:

Parece claro, no entanto, que não é todo interesse público que merece a atenção do Parquet. O interesse público que existe na correta aplicação da lei pelo Juiz, presente em todos os processos, não é, por exemplo, suficiente para ensejar a intervenção ministerial.

(...)

Deve o Ministério Público, então, zelar apenas pelo interesse público que se apresenta como mais relevante, porque relevantes são suas incumbências constitucionais. Assim, se ao Parquet incumbe "a defesa da ordem jurídica, do regime democrático, e dos interesses sociais e individuais indisponíveis", apenas o interesse público qualificado deve merecer sua fiscalização no processo civil, sob pena de um perigoso desvirtuamento da missão constitucional da Instituição, que parece ser a de autêntica alavanca, procurando sempre a efetiva aplicação da lei para propiciar o fortalecimento do Estado de Direito e a pacificação social. (FERRAZ; GUIMARÃES JÚNIOR, 1997, p.155).

A consequência da falta de intervenção do Ministério Público como fiscal da ordem jurídica é a nulidade do processo, como preceituam os artigos $279^{5}$, caput, $\$ 1^{\circ}$ e $\S 2^{\circ}$ e 967 , III, "a" ${ }^{\prime \prime}$, do Novo Código de Processo Civil. É necessário apenas ressaltar a diferença existente quando o Parquet atua em razão do objeto, onde a nulidade é absoluta, e quando a intervenção é necessária apenas em função da qualidade da parte, onde a nulidade ficará condicionada à existência de ocorrer prejuízo ou não.

5 Cf. Art. 279. É nulo o processo quando o membro do Ministério Público não for intimado a acompanhar o feito em que deva intervir.

Parágrafo único. Se o processo tiver corrido, sem conhecimento do Ministério Público, o juiz o anulará a partir do momento em que o órgão devia ter sido intimado.

\$ $\mathbf{1}^{\circ}$ Se o processo tiver tramitado sem conhecimento do membro do Ministério Público, o juiz invalidará os atos praticados a partir do momento em que ele deveria ter sido intimado.

§ $\mathbf{2}^{\circ}$ A nulidade só pode ser decretada após a intimação do Ministério Público, que se manifestará sobre a existência ou a inexistência de prejuízo.

6 Cf. Art. 967. Têm legitimidade para propor a ação rescisória:

III - o Ministério Público:

a) se não foi ouvido no processo em que lhe era obrigatória a intervenção; 


\subsection{A necessidade de intervenção do Ministério Público na ação de usucapião}

O Código de Processo Civil de 1973 tratava a usucapião no Livro IV dos Procedimentos Especiais, Título I, de Jurisdição Contenciosa. Com o advento do Código de Processo Civil atual, a usucapião saiu do Livro IV, pois o que tornava a usucapião um procedimento especial era a audiência de justificação de posse, que foi suprimida através da Lei 8.951/94, dando nova redação ao artigo 942, deixando de se exigir a realização da audiência de justificação de posse.

Progressivamente, foi suprimido o artigo 944 do Código de Processo Civil de 1973, que exigia a intervenção obrigatória do Ministério Público em todos os atos do processo de usucapião, sob pena de nulidade. Atualmente, a usucapião é um procedimento ordinário, e o Novo Código de Processo Civil trata em apenas 3 (três) artigos: 246, 259, §3ㅇ e 1.071 .

A saída expressa da participação do Ministério Público na usucapião, no nosso entendimento, não significa sua prescindibilidade, uma vez que a usucapião é uma ação complexa, onde vários requisitos legais são exigidos, e o promotor de justiça que já atuou na primeira instância nesta ação, sabe da dificuldade de se trazer aos autos a documentação necessária para o cumprimento de todos os pressupostos legais.

A fim de provar que comporta e é necessária a participação do Ministério Público na ação de usucapião, basta fazer uma interpretação sistêmica, que procura no ordenamento jurídico a completude, busca a segurança jurídica, evitando a interpretação de forma a permitir a existência de normas antinômicas e assim ostentar coerência dentro do próprio sistema. Interpreta-se a lei, levando em consideração os demais dispositivos legais existentes.

É fundamental também fazer uma interpretação teleológica, onde se busca encontrar a finalidade da norma, o bem comum, o interesse 
público, a justiça, o valor ou bem jurídico visado pelo ordenamento ao editar a norma, como consta no artigo $5^{\circ}$ da Lei de Introdução às Normas do Direito Brasileiro, a qual propõe ao juiz que, na aplicação da lei, deve atender aos fins sociais a que ela se dirigir e às exigências do bem comum.

A propriedade que pode ser de direito individual privado, tem efeito erga omnes, é de interesse de toda a coletividade, devendo, portanto, o Ministério Público fiscalizar a sua legalidade, sob pena de contribuir para o crescimento das irregularidades fundiárias, como invasões ou mesmo propriedades adquiridas de forma clandestina.

A realidade social em que vivemos, onde não existe muito compromisso de lealdade entre os homens, onde constantemente se busca violar o direito do outro, principalmente no que concerne à propriedade, seja por meio de invasões seja pela burla de documentos, torna-se cada vez mais séria a necessidade de intervenção do Ministério Público como agente promovedor da correta aplicação da lei e da justiça social a ser preservada. Para isso, basta analisarmos os dispositivos contidos nos artigos 178, III, e 176, do Novo Código de Processo Civil:

Art. 176. O Ministério Público atuará na defesa da ordem jurídica, do regime democrático e dos interesses e direitos sociais e individuais indisponíveis.

Art. 178. O Ministério Público será intimado para, no prazo de 30 (trinta) dias, intervir como fiscal da ordem jurídica nas hipóteses previstas em lei ou na Constituição Federal e nos processos que envolvam:

III - litígios coletivos pela posse de terra rural ou urbana. (BRASIL, Código de Processo Civil).

Por certo, a intervenção do Ministério Público como fiscal do ordenamento jurídico na ação de usucapião contribuirá para dar maior segurança jurídica, com a correta aplicação da lei, a fim de se conquistar um ideal de justiça social. 


\section{ASPECTOS POLÊMICOS DA USUCAPIÃO EXTRAJUDICIAL}

A usucapião extrajudicial é o resultado da busca constante por maior celeridade processual no intuito de fornecer uma solução rápida com uma prestação jurídica efetiva, a exemplo da retificação de registro, regularização fundiária, divórcio e inventário, realizados de forma administrativa.

O processo de desjudicialização iniciou com a Lei 11.441/07, denominada Lei da Desburocratização dos Procedimentos, retirando do judiciário a exclusividade da prestação jurisdicional, compartilhando-a com a esfera administrativa.

Inobstante a existência dos princípios que norteiam a função registral imobiliária, tais como legalidade, especialidade, continuidade, presunção e atribuição territorial que garantem o exercício de tal função, resta analisar se os tabeliães e seus funcionários estão preparados para agir de forma imparcial e com os conhecimentos técnico-jurídicos necessários, já que nem todos passaram pelo processo de concurso, a fim de se evitar injustiças ou mesmo o descumprimento da lei. Há necessidade, em muitos casos, de ouvir testemunhas. Terá o tabelião preparo para indeferir as testemunhas impedidas, incapazes ou suspeitas?

Nesse sentido, salienta Brandelli:

Ao Notário cabe acolher e instrumentalizar declarações de
vontade, ou autenticar fatos. Não cabe presidir processos
administrativos, analisando provas e deferindo ou não o
pedido, publicizando o direito ou negando tal publicidade.
(...)
Embora o Notário tenha um papel importante na lavratura
da ata notarial que instruírá a peça inicial do processo, sua
atuação é a de autenticar fatos ou instrumentalizar atos
jurídicos e não a de conduzir processos administrativos
ligados à aquisição de direitos reais; ademais, atua ele na
esfera obrigacional do Direito (BRANDELLI, 2016, p. 18).

Existe segurança jurídica no fornecimento da ata notarial lavrada pelo tabelião atestando o tempo de posse do requerente e seus 
antecessores, conforme art. 216-A, I?

Como avaliar o pressuposto necessário para a ação de usucapião que exige as obras ou serviços de caráter produtivo ou mesmo interesse social e econômico, análise essa que deve ser feita de modo imparcial e com conhecimentos jurídicos específicos?

A obrigação da presença de advogado ou defensor público constitui outra dificuldade em face da precariedade da Defensoria Pública no nosso país, que não possui boa infraestrutura e nem número suficiente de advogados para atender à população.

Resta analisar se a usucapião extrajudicial é modo efetivo e seguro para garantir os interesses sociais da coletividade, tendo em vista que os serviços notariais e de registro não fazem parte do Poder Judiciário e são passíveis de sofrer influências políticas e monetárias por parte do interessado, já que a delegação de um serviço público para particulares pode favorecer ou dificultar a prática desses atos que exigem imparcialidade.

\section{CONCLUSÃO}

O perfil traçado pela Constituição de 1988 não teve por objetivo retirar o Ministério Público de sua atuação nos processos judiciais de interesses individuais. O constituinte aperfeiçoou e acrescentou a defesa dos direitos transindividuas, sejam coletivos, difusos ou individuais homogêneos. Seria um retrocesso suprimir a atuação do Ministério Público nos processos judiciais como fiscal do ordenamento jurídico e como parte, para restringir a sua atuação aos direitos e interesses metaindividuais ou coletivos lato-sensu.

É imprescindível a intervenção do Ministério Público no processo de usucapião tanto judicial quanto extrajudicial como forma de fiscalizar o ordenamento jurídico, tendo em vista a concretização da função social da propriedade e do direito à moradia, contribuindo para o cumprimento do tão almejado princípio da dignidade da pessoa humana.

Não é necessário que a Lei, de forma expressa, exija a intervenção 
do Ministério Público na ação de usucapião, uma vez que o artigo 178 do Código de Processo Civil menciona claramente que o Parquet deve intervir como fiscal da ordem jurídica nas hipóteses em que exista interesse público ou social e nos litígios coletivos pela posse de terra rural ou urbana.

Para isso, basta aplicar a interpretação sistêmica e teleológica, que procura no ordenamento jurídico a completude, busca a segurança jurídica, evitando a interpretação de forma a permitir a existência de normas antinômicas e assim ostentar coerência dentro do próprio sistema. Interpreta-se a lei, levando em consideração os demais dispositivos legais existentes.

Na usucapião extraordinária, que possui natureza administrativa, torna-se fundamental a atuação do Ministério Público como fiscal do ordenamento jurídico, uma vez que a propriedade é de direito privado e disponível, mas a sua função social é de direito coletivo, possuindo efeito erga omnes, sendo claro o interesse público e social.

Mudanças urgentes são necessárias, uma vez que a violência cresce a cada dia, assassinatos são cometidos a qualquer tempo e hora, sequestros e outras formas de atrocidades são praticadas e os direitos sociais estão sendo constantemente violados, em destaque especial ao direito à moradia, tendo em vista as invasões recorrentes e o crescimento das favelas tanto no setor urbano como no rural.

\section{INDISPENSABILITY OF PUBLIC MINISTRY INTERVENTION ON ADVERSE POSSESSION}

\section{ABSTRACT}

Law No. 13.105, of March 16, 2015, establishing the new Civil Procedure code removed the adverse possession from the special procedures of contentious jurisdiction, becoming part of the ordinary procedure, besides innovating about extrajudicial adverse possession, which has an administrative nature. Also suppressed the article dealing with the 
intervention of the Public Ministry in the adverse possession lawsuit. We'll discuss in this article the intervention of the public prosecutor in both judicial an extrajudicial adverse possession as a way of monitoring the legal system, in view of the adverse possession as the embodiment of the social function of property and the right to housing. We'll analyze, finally, the controversial points about the extrajudicial adverse possession.

Keywords: Civil Procedure. Adverse possession. Public ministry intervention. Social function of property. Law no 13.105/2015.

\section{REFERÊNCIAS}

BRASIL, Código de Processo Civil: Lei $n^{\circ}$ 13.105, de 16 de Março de 2015. Institui o Código de Processo Civil. Disponível em: http://www. planalto.gov.br/ccivil_03/_ato2015-2018/2015/lei/113105.htm - Acesso em: 03 abr. 2016.

Código de Processo Civil: Lei 5.868, de 11 de janeiro de 1973. Institui o Código de Processo Civil. Disponível em: http://www.planalto.gov. br/ccivil_03/leis/L5869.htm Acesso em 20 de mai. de 2016.

Código Civil: Lei 10.406, de 10 de janeiro de 2002. Institui o Código Civil. Disponível em: http://www.planalto.gov.br/ccivil_03/leis/2002/ 110406.htm Acesso em 20 de mai. de 2016.

Constituição da República Federativa do Brasil de 1988. Disponível em: http://www.planalto.gov.br/ccivil_03/constituicao/constituicao. htm Acesso em 15 de mai. de 2016.

Pacto Internacional de Direitos Econômicos, Sociais e Culturais, Decreto n 591, de 6 de julho de 1992. Disponível em: http:/ /www.planalto.gov.br/ccivil_03/decreto/1990-1994/d0591.htm. Acesso em: 05 jul. 2016.

BRANDELLI, Leonardo. Usucapião administrativa: De acordo com o 
Novo Código de Processo Civil. São Paulo: Saraiva. 2016, p. 18.

BULOS, Uadi Lammêgo. Constituição Federal anotada. 7 ed. Editora Saraiva. São Paulo - São Paulo. 2007, p. 197.

DA CUNHA JR, Dirley; NOVELINO, Marcelo. Constituição Federal para Concursos. 6 ed. Editora Juspodvm. Salvador - Bahia. 2015, p. 169.

FERRAZ, Antônio Augusto Mello de Camargo; GUIMARÃES JÚNIOR, João Lopes. Ministério Público - Instituição e Processo. São Paulo, Ed. Atlas, 1997, pág. 155.

GONÇALVES, Carlos Roberto. Direito Civil Brasileiro - Direito das Coisas. Volume V, 4a Edição. São Paulo: Saraiva, 2006, p.99.

GONÇALVES, Marcos Vinicius Rios. Direito Processual Civil Esquematizado. 7 ed. São Paulo. Saraiva. 2016, p. 279.

MALUF, Adriana Caldas do Rego Freitas Dabus. Limitações urbanas ao direito de propriedade. São Paulo: Atlas, 2010. p. 60 e 61.

MAZILLI, Hugo Nigro. Manual do promotor de justiça. 2 ed. São Paulo. Saraiva. 1991, p.1.

NEVES, Daniel Amorim Assumpção. Manual de Direito Processual Civil. 4 ed. Rio de Janeiro: Forense. São Paulo: MÉTODO, 2012, p. 1387.

SALLES, José Carlos de Moraes. Usucapião de bens imóveis e móveis. 6 ed., São Paulo: Revista dos Tribunais, 2005, p. 49.

Usucapião de bens imóveis e móveis. 4 ed., São Paulo: Revista dos Tribunais, 1997, p.31. 